\title{
Biomarkers for Infants at Risk for Necrotizing Enterocolitis: Clues to Prevention?
}

\author{
CHRISTOPHER YOUNG, RENU SHARMA, MARTIN HANDFIELD, VOLKER MAI, AND JOSEF NEU \\ Department of Pediatrics [C.Y., J.N.], Department of Microbiology [V.M.], Department of Oral Biology and Center for Molecular \\ Microbiology [M.H.], University of Florida, Gainesville, Florida 32610; Department of Pediatrics [R.S.], University of Florida, \\ Jacksonville, Florida 32209
}

\begin{abstract}
Necrotizing enterocolitis (NEC) is the most common severe gastrointestinal emergency that affects premature newborns. This disease often has a rapid onset with few, if any, antecedent signs that can be used to reliably predict its occurrence. Its rapid onset and progression to death, as well as its severe morbidity when the infant survives, begs for early diagnostic tools that may be used in determining those infants who would be at greatest risk for development of the disease and for whom early preventative measures could be targeted. Although studies have suggested efficacy of several techniques such as breath hydrogen, inflammatory mediators in blood, urine or stool, and genetic markers, these all have drawbacks limiting their use. The application of newly developed "omic" approaches may provide biomarkers for early diagnosis and targeted prevention of this disease. (Pediatr Res 65: 91R-97R, 2009)
\end{abstract}

$\mathrm{N}$ ecrotizing enterocolitis (NEC) is the most common severe gastrointestinal (GI) disease that predominantly afflicts premature infants in neonatal intensive care units (NICUs). Of 2500 annual cases reported in the United States, $20-60 \%$ undergo surgery and $20-28 \%$ do not survive $(1,2)$. Progress in the prevention of NEC has been limited by difficulties in clearly defining the condition and by our inability to identify subsets of premature infants at highest risk of developing NEC (3). Part of the difficulty stems from the heterogeneity in what is termed NEC. In term and late preterm infants, what has been termed "NEC" has a greater association with predisposing factors such as low Apgar scores, chorioamnionitis, exchange transfusions, prolonged rupture of membranes, congenital heart disease, and neural tube defects (4). Spontaneous intestinal perforation frequently is not accompanied by significant intestinal necrosis, occurs earlier than NEC, and is associated with the combined use of glucocorticoids and indomethacin $(5,6)$. Here, we will focus on "classic" NEC that is generally seen in premature infants born at less than 32 wk of gestation and with a birth weight of less than $1500 \mathrm{~g}$. The increased susceptibility has been attributed to multifactorial etiologies including an immature mucosal barrier and barrier inflammatory response, genetic susceptibility,

Received November 3, 2008; accepted December 17, 2008.

Correspondence: Josef Neu, M.D., 1600 S.W. Archer Road, Box 100296, Gainesville, Florida, 32610; e-mail: neuj@peds.ufl.edu

Supported in part by the National Institute of Child Health grant number R01 HD 059143 and an educational grant to M. Mshvildadge from the European Society for Pediatric Research. dysfunctional intestinal microecology, and idiosyncrasies related to aggressive feeding practices $(7,8)$.

Previously, the diagnosis of NEC was based on criteria first established by Bell et al. (9) in 1978, which are limited to the clinical and radiographic appearance of the infant. Newer criteria, such as the modified Bell system proposed by Walsh and Kleigman (10), have incorporated the original criteria with laboratory findings to more clearly classify NEC, aiding in diagnosis and therapy. Even more recently, the addition of gray scale and color Doppler ultrasonography to the diagnostic arsenal has enhanced our ability to diagnose NEC, especially in cases with inconclusive plain film radiography or nonspecific clinical presentations (11). However, all of the above diagnostic criteria and modalities are applicable only after the infant has developed signs or symptoms of the disease. But because of its delayed occurrence after birth and its highly fulminant nature, identifying prospective biomarkers specific for high NEC risk would offer opportunities for early intervention. In addition to being associated with NEC risk, such biomarkers should be noninvasive, easy to obtain, and inexpensive. Here, we will first review several previously published methods (summarized in Table 1) and then discuss selected emerging technologies that may help us identify infants at risk for NEC and to prevent this devastating disease.

\section{Previously Studied Techniques}

Breath hydrogen sampling. Microbial fermentation of unabsorbed carbohydrates results in production of hydrogen $\left(\mathrm{H}_{2}\right)$ gas that, although partially used by $\mathrm{H}_{2}$ consuming intestinal microbes, is assimilated into the bloodstream and eventually exhaled. Previous studies have suggested that this technique could be used in the early detection of NEC (12). In one study, breath $\mathrm{H}_{2}$ excretion was determined in 122 neonates from birth to 1 mo of age (12). The patients weighed less than $2000 \mathrm{~g}$ at birth and thus were at risk for developing NEC. Hydrogen excretion was normalized for the quality of the expired air by dividing the exhaled hydrogen pressure by the carbon dioxide $\left(\mathrm{CO}_{2}\right)$ pressure of the gas sample. The mean ( $\pm \mathrm{SD}$ ) peak $\mathrm{H}_{2} / \mathrm{CO}_{2}$ ratio was greater in seven infants who subsequently developed NEC $(9.4 \pm 2.7 \mathrm{ppm} / \mathrm{mm} \mathrm{Hg})$ than

Abbreviations: CRP, C-reactive protein; GI, gastrointestinal; I-FABP, intestinal fatty acid binding protein; IGF-1, Insulin-like growth factor 1; NEC, necrotizing enterocolitis; SNP, single-nucleotide polymorphism; VLBW, very low birth weight 
YOUNG $E T A L$.

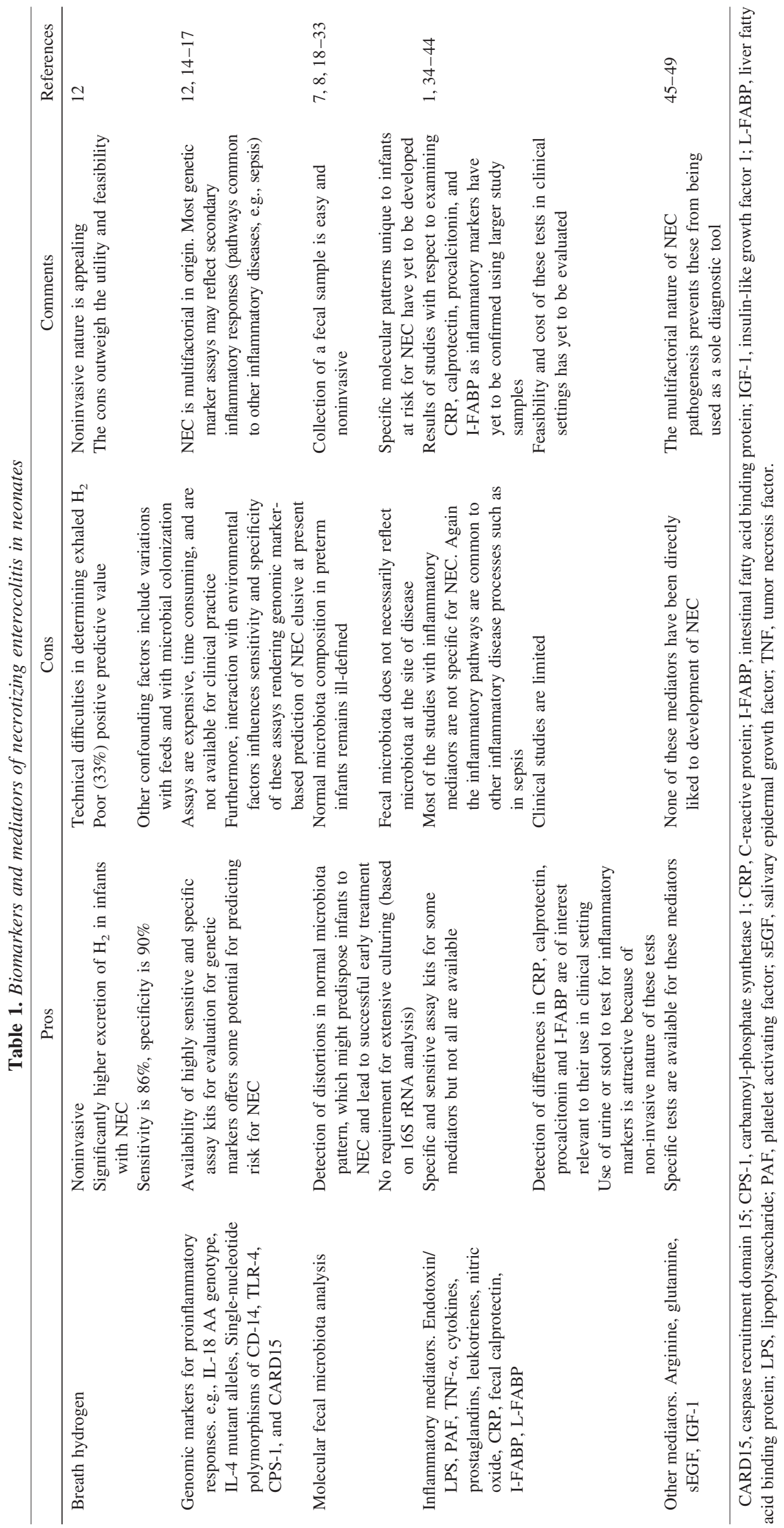


the 115 infants who did not $(5.0 \pm 3.5 \mathrm{ppm} / \mathrm{mm} \mathrm{Hg})$. Defining a positive test as one with a ratio value of $\geq$ to $8.0 \mathrm{ppm} / \mathrm{mm}$ $\mathrm{Hg}$, the resulting screening test had a sensitivity of $86 \%$ and a specificity of $90 \%$. The screening test yielded a $33 \%$ predictive value for a positive test and a $99 \%$ predictive value for a negative test. Increased $\mathrm{H}_{2}$ excretion occurred 8-28 h before the onset of the earliest clinical signs of NEC. It was initially concluded that breath $\mathrm{H}_{2}$ excretion is a simple noninvasive test that may be useful in the management of the premature neonate at risk for the development of NEC. However, this test has not received acceptance largely because of technical difficulties in measuring the pressure of exhaled hydrogen, the large variations in food intake, the variability in the time it takes for bacterial colonization, and the poor predictive value for a positive test.

Genomic markers. Analyses of twin gestations support that intraventricular hemorrhage, NEC, and bronchopulmonary dysplasia are familial in origin (13). Given this genetic predisposition, finding a genetic marker that is sensitive, specific, and predictive could be a valuable adjunct to early identification and prevention of NEC. Because of the potential that inadequate innate immune responses to bacterial antigens in the intestinal flora may play a role in the development of NEC, single-nucleotide polymorphisms (SNPs) of CD-14, TLR-4 (toll like receptor-4), and caspase-recruitment domain 15 were analyzed in very low birth weight (VLBW) infants with and without NEC, but found not to be associated with increased risk (14). However, another group of investigators focused more specifically on the TLR-4 gene. This gene, responsible for part of the proinflammatory cascade, was studied in a murine model of NEC, and its products were found to be present in higher levels in those animals at risk for developing NEC, and animals with a mutant TLR-4 gene had a decreased incidence of the disease (15). These findings suggested that gene products, not a SNP alone, might be of more prognostic utility. However, a SNP in the gene that encodes carbamoyl-phospate sythetase 1 (CPS1), the ratelimiting enzyme in the production of arginine, was found to be associated with an increased risk of NEC development (16).

The risk for NEC has also been associated with the frequency of the interleukin (IL)- $18^{607}$ AA genotype (12). The frequency of the AA genotype is significantly higher in infants with stage III NEC compared with stages I and II (17). Thus, the presence of AA genotype may adversely affect the outcome of NEC through altered IL-18 levels, a cytokine that induces interferon- $\gamma$ and amplifies T-helper cell type 1 (Th1) cytokine production and IL-8 accumulation (17). VLBW infants with NEC were also shown to be less likely to possess the IL-4 receptor $\alpha$-chain mutant allele compared with infants without NEC (17). The variant of $I L-4$ receptor gene is associated with enhanced transduction of IL-4 signals, which shifts the development of lymphocytes to a more pronounced Th cell type 2 (Th2) state (17). It is speculated that the elevated number of Th2 cells in carriers of this genetic polymorphism is a protective factor against the development of NEC (17).

These findings suggest that NEC is mediated not by genetics alone, but by genetic factors in conjunction with host- bacteria interactions. Thus, the search for genetic markers appears to have some potential, but sensitivity and specificity for prediction remains elusive largely because of the interaction with environmental factors that also appear to play an important role in the pathogenesis of NEC.

Intestinal microbiota. Colonization of the GI tract of the newborn with microorganisms from the extrauterine environment starts immediately after birth and is markedly affected by maternal and environmental microbial sources. The frequent use of antibiotics, type of feeding (human milk versus formula), mode of delivery (vaginal versus Caesarian section), and various manipulations in the NICU, such as nursing in an incubator versus under radiant warmers, have the potential to alter the intestinal microbiota (18-20). Recent technologic advances reveal that although the majority of microbes in the human GI tract cannot yet be cultured, powerful new molecular 16S ribosomal RNA-based techniques now allow for a comprehensive analysis of microbiota $(21,22)$. The vast array of commensal microorganisms with their immense metabolic capabilities contributes significantly to host physiology. Microbiota contributions include vitamin synthesis, nutrient utilization and absorption, stimulation of immune responses to pathogens as well as tolerance to luminal antigens, and stimulation of Paneth cell peptide secretion, which in turn, promotes angiogenesis, growth, and an environment that facilitates colonization by commensals rather than opportunistic pathogenic microorganisms $(23,24)$. However, a different situation appears in the premature infant wherein microbes, although essential for normal intestinal growth and development, are also implicated in the development or exacerbation of NEC (7).

The large diversity of bacteria present in infants even before the development of NEC and the current failure to isolate/ identify a known pathogen suggests that commensal microbes are usually bystanders that, under certain conditions, can amplify pathologic processes such as uncontrolled inflammation. A related hypothesis is that a particular microbiota composition, which might be normal in a full term infant, may be the culprit leading to the inappropriate inflammatory cascade producing NEC in preterm babies as opposed to the presence of particular pathogenic species $(7,8)$. There is older evidence, however, showing that specific changes can be observed in the intestinal flora preceding the development of NEC (25). Hence, it is apparent that the microbial ecology is a factor in the development of NEC, but a definitive causality has yet to be determined.

When infants with NEC were compared with control infants without NEC (matched for gestational age at birth and postmenstrual age), a study based on cultivating potential pathogens did not detect specific bacteria associated with disease (26). This observation does not exclude the possibility that sufficiently powered studies that use modern molecular microbiota analysis methods could identify pathogens in the future. In addition to specific pathogens, the colonization with a microbiota altered in its diversity or emergence of dominant commensal microbes that elucidate an inappropriate immune response may be of importance in the disease process (27). Recent studies using molecular techniques have provided 
initial insight (28). The use of $16 \mathrm{~S}$ ribosomal RNA-based approaches has greatly facilitated the study of GI tract microbial ecology because it circumvents the need for culturing (29). Powerful novel molecular approaches, including pyrosequencing, now allow for an in depth analysis reaching saturation that can detect sequence signatures for bacteria contributing only a small proportion to the overall microbiota (29).

These new molecular microbiota-typing techniques for the detection of otherwise noncultivatable microbes offer new opportunities for delineating both specific NEC-associated pathogens as well as intestinal microecologic patterns that may be conducive to the pathogenesis of NEC. There have been arguments against the validity of using fecal microbiota as a surrogate temporal measure for the microbiota that is in close contact to the small and large intestinal mucosa. Preterm babies defecate infrequently and thus distortions in microbiota composition might not be detected in rectal swabs or stool specimens when inflammation is either starting or progressing at the intestinal mucosal surface.

Recently, there has been an interest in altering the intestinal microbiota to manipulate disease. Studies of antibiotics (30), prebiotics $(31)$, and probiotics $(32,33)$ have been carried out in the hopes of developing a prophylactic therapy for NEC. Although there has been no conclusive evidence of definitive preventive strategies, much remains to be discovered in the realm of manipulation of the microflora.

Inflammatory mediators. Similar to sepsis and adult respiratory distress syndrome, the pathogenesis of NEC appears to involve a pathway that includes the endogenous production of inflammatory mediators involved in the development of intestinal injury (34). Endotoxin/lipopolysaccharide (LPS), platelet-activating factor (PAF), tumor necrosis factor alpha (TNF- $\alpha$ ), IL-8, and other chemokines and cytokines, together with prostaglandins, leukotrienes, and nitric oxide, are thought to be involved in the final common pathway of NEC pathogenesis $(1,34,35)$. Sera, tissue, stool, or other samples from early time points in the development of the disease may help delineate early inflammatory events that predispose an infant to NEC, thus providing an interventional opportunity. Here, we will briefly review some of the inflammatory and other markers that have been and/or are still being evaluated for the early diagnosis of NEC.

In one study, concentrations of IL- $1 \beta$, IL-6, endotoxin/LPS, and TNF- $\alpha$ were measured at the onset of clinical illness (35). Neonatal endotoxemia and release of proinflammatory cytokines were found to be important contributors to multiple organ failure and mortality. Endotoxemia was most severe at the onset of illness among the infants with NEC, suggesting that gut barrier failure plays an important role in adverse outcomes in the NICU (35).

In another study, association between serum C-reactive proteins (CRP) and NEC were evaluated (36). CRP levels were found to be abnormal in both stage II and stage III NEC. In infants with NEC, persistently elevated CRP after initiation of appropriate medical management suggested development of complications of NEC, which often required surgical intervention.
Another mediator, fecal calprotectin, has also been evaluated as a potential diagnostic tool for NEC. It is an established screening test used in diagnosing inflammatory bowel disease (37) and is now taking on an expanding role in disease monitoring and relapse detection (38). For NEC, levels of fecal calprotectin have been measured in stools of VLBW premature infants. One study showed that a fecal calprotectin level $>2000 \mu \mathrm{g} / \mathrm{g}$ is a useful, but not an early marker of NEC and of other severe intestinal inflammatory conditions in VLBW infants (39). In another pilot study designed to determine whether it can be used to aid diagnosis of NEC in preterm infants (40), it was found that infants with NEC had greater fecal calprotectin concentrations at the time of diagnosis compared with matched controls $(288.4 \mathrm{mg} / \mathrm{L} \pm 49.1$ versus $98.0 \mathrm{mg} / \mathrm{L} \pm 60.6, p=0.0006)$. These studies were done primarily at the time of onset of NEC. In another study (41), fecal calprotectin levels of 14 VLBW infants (gestational age $23-30 \mathrm{wk}$, birth weight $\leq 1500 \mathrm{~g}$ ) were serially measured in the first postnatal month. Fecal calprotectin levels significantly differed between "well" and "sick" infants (122.8 98.9 versus $380.4 \pm 246.3 \mu \mathrm{g} / \mathrm{g}$ stool, $p<0.001)$. A fecal calprotectin level $>350 \mu \mathrm{g} / \mathrm{g}$ stool was associated when signs of GI injury, such as bloody stool or bowel perforation, were present. Levels decreased after initiation of treatments in sick infants who recovered. These studies concluded that fecal calprotectin levels may be a marker for early diagnosis and resolution of GI illness in VLBW infants, but its utility for early diagnosis and assessment of resolution of NEC needs to be studied in a larger cohort of VLBW infants.

Fatty acid binding proteins, tissue-specific inflammatory markers usually found to be more elevated during periods of ischemia, have also been evaluated as potential markers for the diagnosis and staging of NEC. Specifically, in a recent study by Guthmann et al. (42), plasma concentrations of both intestinal fatty acid binding protein (I-FABP) and liver fatty acid binding protein were measured in healthy preterm infants and in preterm infants with NEC. I-FABP was found to be associated with advanced stages of NEC, whereas liver fatty acid binding protein was found to be significantly elevated in infants with only a suspicion of NEC (42), indicating that the latter may be a more sensitive marker for the early detection of the disease. Urinary I-FABP as a marker of intestinal injury was evaluated in another study (43). A value of $2 \mathrm{pg} / \mathrm{nmol}$ for the urinary I-FABP to creatinine ratio was capable of distinguishing the group of infants with NEC or intestinal necrosis from the other diagnoses. Given the ease and frequency with which urine can be collected without adverse consequences for the baby, it was concluded that the feasibility of urinary I-FABPs as a screening tool for NEC requires further evaluation in a prospective trial. Although these markers show some promise in diagnosis and classification of disease, much remains to be evaluated before their application in the clinical setting.

It is likely that the lack of diagnostic and therapeutic modalities for NEC is due to the lack of an overall view of the disease. Properly validated and calibrated mathematical models of inflammation and its pathologic consequences in NEC could be useful for predicting the physiologic and biologic 
response in infants suffering from the disease, but, as suggested recently, have not yet been fully developed (44).

Other mediators. Also associated with NEC are low concentrations of arginine and glutamine. Supplementation of each of these amino acids has been considered as a preventative strategy for the disease $(45,46)$. However, these therapies are likely to be nonspecific for NEC and the deficiencies are likely caused by low intakes and high consumption during stress (47).

Finally, growth factors have also been assessed for use not only as diagnostic tools, but also as therapeutic interventions. For diagnostic purposes, a prospective analysis was performed in which levels of salivary-derived epidermal growth factor were found to be significantly lower in preterm infants, and more rapid elevations of salivary-derived epidermal growth factor during the first weeks of life were associated with a greater incidence of NEC (48). For therapeutic purposes, another study evaluated levels of insulin-like growth factor 1 (IGF-1) and its effects on maturation of intestinal function in preterm infants (49). It was suspected that supplementation of IGF-1 in preterm formulas would speed the growth and development of the barrier and absorptive features of the gut (49), thereby potentially decreasing the likelihood of NEC development. However, supplementation was not found to be substantially beneficial, possibly because of synergy with other factors that were not supplemented in conjunction with IGF-1 (49). Nevertheless, these important observations suggest the feasibility of developing biomarkers for the early detection of NEC and encourage further investigation.

\section{Emerging Biomarker Technologies}

New molecular techniques have recently emerged in their use to develop biomarkers for diseases such as prostate cancer (50), liver disease (51), infection in the amniotic fluid (52), and for the detection of retinopathy of prematurity (53). Even more promising is the finding that proteomic fingerprinting of amniotic fluid has proven to be more accurate than conventional Gram's stain and culturing in diagnosing intra-amniotic infection (54). Such successes using molecular techniques offer promise to the hope of finding a biomarker for detection, and possibly prevention, of NEC.

Proteomics. Proteomics is a rapidly growing science that focuses on the multitude of tasks assigned to proteins $(54,55)$. It relates to the structure, the functions, and the interactions of proteins including their identification and quantification (55). It also entails the study of impact of their interactions on biologic functions. In VLBW infants susceptible to NEC, it is likely that on account of premature birth, the developing proteins are disharmonized and that either the signaling pathways between microbiota and the intestinal barrier or the trafficking of luminal matter through the intestinal barrier is altered in a manner that is conducive to the genesis of NEC (56).

Proteomic technologies involve several steps. Polyacrylamide and two-dimensional gel (2D gel) electrophoresis methods of protein separation exploit the protein property that, in the presence of an electric field, the intrinsic charge of proteins impart a characteristic electrophoretic mobility to them permitting their separation and identification based on their mo- lecular weights and net charge (57). Of these two, the method of $2 \mathrm{D}$ gel is considered a better option for high-resolution profiling of low abundance proteins in the quest for identifying biomarkers for NEC (58).

Mass spectrometry is another powerful technique emerging in the field of diagnostic biomarkers and identification of proteins involved in diseases (59). This technique involves introducing enough energy into a target molecule to cause its ionization and disintegration. The resulting fragments are then analyzed, based on the mass/charge ratio. Different types of mass spectrometry techniques, including surface-enhanced laser desorption/ionization time-of-flight mass spectrometry, matrix-assisted laser desorption/ionization time-of-flight mass spectrometry, and tandem mass spectroscopy (MS/MS), are available $(57,59)$. Two-dimensional gel is often used in conjunction with mass spectrometry $(55,57)$. One such example is the detection of potential biomarkers characteristic of premature rupture of membranes in preterm deliveries (54). The Figure 1 illustrates how these techniques might be used in human babies.

Transcriptomics. Transcriptomics is a global way of evaluating gene-expression patterns (60). It involves study of all mRNA molecules, or transcripts, and evaluation of changes in transcription initiation, processing, and degradation of proteins. The technique of polymerase chain reaction (PCR), based on transcriptomics, holds promise in discovering biomarkers in the area of NEC research in the near future. PCR is already being used to help identify previously uncultivatable organisms $(21,29,61)$. The collection of samples adequate for PCR is appealing as minute amounts of biologic material are all that are required as they are amplified further during this process $(60,61)$. Samples can be obtained from almost any tissue such as skin, saliva, and buccal scrapings without undue extensive invasive tests or blood sampling.

These new methods are not, however, without their share of challenges. One of the most obvious is the need for proper instrumentation. Accurate and affordable equipment must be available for efficient application of these techniques. If a previously unknown gene is found to be differentially ex-

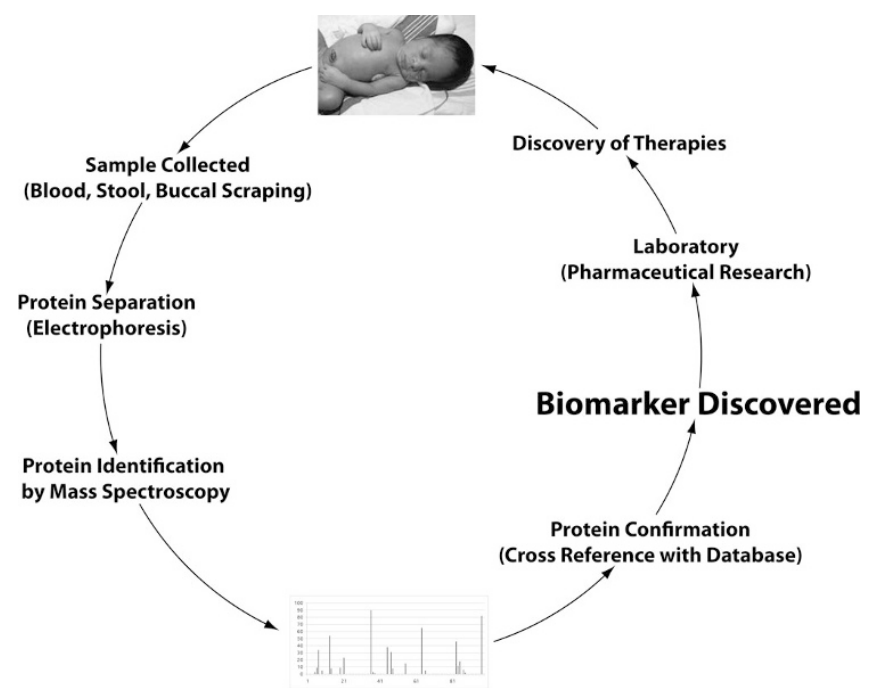

Figure 1. The biomarker discovery process. 
pressed in health versus disease, it remains critical that the corresponding gene product be confirmed both phenotypically and at the protein level. Although the technology is available to perform this type of evaluation, the bottleneck in developing a good diagnostic platform derives from issues related to finding statistical significance and biologic relevance of a differentially transcribed gene.

\section{Conclusion}

Emerging evidence suggests that major pathophysiologic contributions to the development of NEC originate from a defective interaction between intestinal microbes and the host's response to these microbes. Newly developed technologies supported by initiatives such as the human microbiome project are likely to provide new information. "Omic-based" techniques for biomarker discovery in tissue samples obtained noninvasively appear particularly appealing for the development of novel point-of-care diagnostic markers and are attractive for the development of effective therapies, such as nutritional supplements (growth factors, prebiotics, etc.), bacterial manipulations (probiotics, antibiotics), or even direct therapy with recombinant gene products to reduce or eliminate the inflammatory response.

\section{REFERENCES}

1. Hsueh W, Caplan MS, Qu XW, Tan XD, De Plaen IG, Gonzalez-Crussi F 2003 Neonatal necrotizing enterocolitis: clinical considerations and pathogenetic concepts. Pediatr Dev Pathol 6:6-23

2. Lin PW, Stoll BJ 2006 Necrotising enterocolitis. Lancet 368:1271-1283

3. Grave GD, Nelson SA, Walker WA, Moss RL, Dvorak B, Hamilton FA, Higgins R, Raju TN 2007 New therapies and preventive approaches for necrotizing enterocolitis: report of a research planning workshop. Pediatr Res 62:510-514

4. Martinez-Tallo E, Claure N, Bancalari E 1997 Necrotizing enterocolitis in full-term or near-term infants: risk factors. Biol Neonate 71:292-298

5. Stark AR, Carlo WA, Tyson JE, Papile LA, Wright LL, Shankaran S, Donovan EF, Oh W, Bauer CR, Saha S, Poole WK, Stoll BJ, Fanaroff AA, Ehrenkranz RA, Korones SB, Stevenson DK 2001 Adverse effects of early dexamethasone treatment in extremely-low-birth-weight infants. N Engl J Med 344:95-101

6. Attridge JT, Clark R, Walker MW, Gordon PV 2006 New insights into spontaneous intestinal perforation using a national data set: (2) two populations of patients with perforations. J Perinatol 26:185-188

7. Neu J 2005 Neonatal necrotizing enterocolitis: an update. Acta Paediatr Suppl 94:100-105

8. Neu J, Douglas-Escobar M, Lopez M 2007 Microbes and the developing gastrointestinal tract. Nutr Clin Pract 22:174-182

9. Bell MJ, Ternberg JL, Feigin RD, Keating JP, Marshall R, Barton L, Brotherton T 1978 Neonatal necrotizing enterocolitis. Therapeutic decisions based upon clinical staging. Ann Surg 187:1-7

10. Walsh MC, Kliegman RM 1986 Necrotizing enterocolitis: treatment based on staging criteria. Pediatr Clin North Am 33:179-201

11. Epelman M, Daneman A, Navarro OM, Morag I, Moore AM, Kim JH, Faingold R, Taylor G, Gerstle JT 2007 Necrotizing enterocolitis: review of state-of-the-art imaging findings with pathologic correlation. Radiographics 27:285-305

12. Cheu HW, Brown DR, Rowe MI 1989 Breath hydrogen excretion as a screening test for the early diagnosis of necrotizing enterocolitis. Am J Dis Child 143:156-159

13. Bhandari V, Bizzarro MJ, Shetty A, Zhong X, Page GP, Zhang H, Ment LR, Gruen JR; Neonatal Genetics Study Group 2006 Familial and genetic susceptibility to major neonatal morbidities in preterm twins. Pediatrics 117:1901-1906

14. Szebeni B, Szekeres R, Rusai K, Vannay A, Veres G, Treszl A, Arato A, Tulassay T, Vasarhelyi B 2006 Genetic polymorphisms of CD14, toll-like receptor 4, and caspase-recruitment domain 15 are not associated with necrotizing enterocolitis in very low birth weight infants. J Pediatr Gastroenterol Nutr 42:27-31

15. Jilling T, Simon D, Lu J, Meng FJ, Li D, Schy R, Thomson RB, Soliman A, Arditi M, Caplan MS 2006 The roles of bacteria and TLR4 in rat and murine models of necrotizing enterocolitis. J Immunol 177:3273-3282

16. Moonen RM, Paulussen AD, Souren NY, Kessels AG, Rubio-Gozalbo ME, Villamor E 2007 Carbamoyl phosphate synthetase polymorphisms as a risk factor for necrotizing enterocolitis. Pediatr Res 62:188-190

17. Treszl A, Heninger E, Kalman A, Schuler A, Tulassay T, Vasarhelyi B 2003 Lower prevalence of IL-4 receptor alpha-chain gene G variant in very-low-birth-weight infants with necrotizing enterocolitis. J Pediatr Surg 38:1374-1378
18. Johnson CC, Ownby DR, Alford SH, Havstad SL, Williams LK, Zoratti EM, Peterson EL, Joseph CL 2005 Antibiotic exposure in early infancy and risk for childhood atopy. J Allergy Clin Immunol 115:1218-1224

19. Yan F, Polk DB 2004 Commensal bacteria in the gut: learning who our friends are. Curr Opin Gastroenterol 20:565-571

20. Neu J 2007 Perinatal and neonatal manipulation of the intestinal microbiome: a note of caution. Nutr Rev 65:282-285

21. Frank DN, Pace NR 2008 Gastrointestinal microbiology enters the metagenomics era. Curr Opin Gastroenterol 24:4-10

22. Relman DA 1993 The identification of uncultured microbial pathogens. J Infect Dis 168:1-8

23. Hooper LV, Gordon JI 2001 Commensal host-bacterial relationships in the gut. Science 292:1115-1118

24. Hooper LV, Stappenbeck TS, Hong CV, Gordon J 2003 Angiogenins: a new class of microbicidal proteins involved in innate immunity. Nat Immunol 4:269-273

25. Hoy C, Millar MR, MacKay P, Godwin PG, Langdale V, Levene MI 1990 Quantitative changes in faecal microflora preceding necrotising enterocolitis in premature neonates. Arch Dis Child 65:1057-1059

26. Peter CS, Feuerhahn M, Bohnhorst B, Schlaud M, Ziesing S, von der Hardt H, Poets CF 1999 Necrotising enterocolitis: is there a relationship to specific pathogens? Eur J Pediatr 158:67-70

27. Alverdy JC 2008 The re-emerging role of the intestinal microflora in critical illness and inflammation: why the gut hypothesis of sepsis syndrome will not go away. J Leukoc Biol 83:461-466

28. Butel MJ, Suau A, Campeotto F, Magne F, Aires J, Ferraris L, Kalach N, Leroux B, Dupont C 2007 Conditions of bifidobacterial colonization in preterm infants: a prospective analysis. J Pediatr Gastroenterol Nutr 44:577-582

29. Margulies M, Egholm M, Altman WE, Attiya S, Bader JS, Bemben LA, Berka J, Braverman MS, Chen Y-J, Chen Z, Dewell SB, Du L, Fierro JM, Gomes XV, Godwin BC, He W, Helgesen S, Ho CH, Irzyk GP, Jando SC, Alenquer ML, Jarvie TP, Jirage KB, Kim J-B, Knight JR, Lanza JR, Leamon JH, Lefkowitz SM, Lei M, Li J, Lohman KL, Lu H, Makhijani VB, McDade KE, McKenna MP, Myers EW, Nickerson E, Nobile JR, Plant R, Puc BP, Ronan MT, Roth GT, Sarkis GJ, Simons JF, Simpson JW, Srinivasan M, Tartaro KR, Tomasz A, Vogt KA, Volkmer GA, Wang SH, Wang Y, Weiner MP, Yu P, Begley RF, Rothberg JM 2005 Genome sequencing in microfABRicated high-density picolitre reactors. Nature 437:376-380

30. Bury RG, Tudehope D 2000 Enteral antibiotics for preventing necrotising enterocolitis in low birthweight or preterm infants. Cochrane Database Syst Rev CD000405

31. Danan C, Huret Y, Tessedre AC, Bensaada M, Szylit O, Butel MJ 2000 Could oligosaccharide supplementation promote gut colonization with a beneficial flora in preterm infants? J Pediatr Gastroenterol Nutr 30:217-219

32. Alfaleh K, Bassler D 2008 Probiotics for prevention of necrotizing enterocolitis in preterm infants. Cochrane Database Syst Rev CD005496

33. Embleton ND, Yates R 2008 Probiotics and other preventative strategies for necrotising enterocolitis. Semin Fetal Neonatal Med 13:35-43

34. Markel TA, Crisostomo PR, Wairiuko GM, Pitcher J, Tsai BM, Meldrum DR 2006 Cytokines in necrotizing enterocolitis. Shock 25:329-337

35. Sharma R, Tepas J Jr, Hudak ML, Mollitt DL, Wludyka PS, Teng RJ, Premachandra BR 2007 Neonatal gut barrier and multiple organ failure: role of endotoxin and proinflammatory cytokines in sepsis and necrotizing enterocolitis. J Pediatr Surg 42:454-461

36. Pourcyrous M, Korones SB, Yang W, Boulden TF, Bada HS 2005 C-reactive protein in the diagnosis, management, and prognosis of neonatal necrotizing enterocolitis. Pediatrics 116:1064-1069

37. Sutherland AD, Gearry RB, Frizelle FA 2008 Review of fecal biomarkers in inflammatory bowel disease. Dis Colon Rectum 51:1283-1291

38. D’Inca R, Dal Pont E, Di Leo V, Benazzato L, Martinato M, Lamboglia F, Oliva L, Sturniolo GC 2008 Can calprotectin predict relapse risk in inflammatory bowel disease? Am J Gastroenterol 103:2007-2014

39. Josefsson S, Bunn SK, Domellöf M 2007 Fecal calprotectin in very low birth weight infants. J Pediatr Gastroenterol Nutr 44:407-413

40. Carroll D, Corfield A, Spicer R, Cairns P 2003 Faecal calprotectin concentrations and diagnosis of necrotising enterocolitis. Lancet 361:310-311

41. Yang Q, Smith PB, Goldberg RN, Cotten CM 2008 Dynamic change of fecal calprotectin in very low birth weight infants during the first month of life. Neonatology 94:267-271

42. Guthmann F, Borchers T, Wolfrum C, Wustrack T, Bartholomaus S, Spener F 2002 Plasma concentration of intestinal- and liver-FABP in neonates suffering from necrotizing enterocolitis and in healthy preterm neonates. Mol Cell Biochem 239:227-234

43. Derikx JP, Evennett NJ, Degraeuwe PL, Mulder TL, van Bijnen AA, van Heurn LW, Buurman WA, Heineman E 2007 Urine based detection of intestinal mucosal cell damage in neonates with suspected necrotising enterocolitis. Gut 56:1473-1475

44. Upperman JS, Camerini V, Lugo B, Yotov I, Sullivan J, Rubin J, Clermont G, Zamora R, Ermentrout GB, Ford HR, Vodovotz Y 2007 Mathematical modeling in necrotizing enterocolitis-a new look at an ongoing problem. J Pediatr Surg 42:445-453

45. Amin HJ, Zamora SA, McMillan DD, Fick GH, Butzner JD, Parsons HG, Scott RB 2002 Arginine supplementation prevents necrotizing enterocolitis in the premature infant. J Pediatr 140:425-431

46. Tubman TR, Thompson SW, McGuire W 2008 Glutamine supplementation to prevent morbidity and mortality in preterm infants. Cochrane Database Syst Rev CD001457 
47. Becker RM, Wu G, Galanko JA, Chen W, Maynor AR, Bose CL, Rhoads JM 2000 Reduced serum amino acid concentrations in infants with necrotizing enterocolitis. J Pediatr 137:785-793

48. Warner BB, Ryan AL, Seeger K, Leonard AC, Erwin CR, Warner BW 2007 Ontogeny of salivary epidermal growth factor and necrotizing enterocolitis. J Pediatr 150:358-363

49. Corpeleijn WE, van Vliet I, de Gast-Bakker DA, van der Schoor SR, Alles MS, Hoijer M, Tibboel D, van Goudoever JB 2008 Effect of enteral IGF-1 supplementation on feeding tolerance, growth, and gut permeability in enterally fed premature neonates. J Pediatr Gastroenterol Nutr 46:184-190

50. Wagner M, Naik DN, Pothen A, Kasukurti S, Devineni RR, Adam BL, Semmes OJ, Wright GL 2004 Computational protein biomarker prediction: a case study for prostate cancer. BMC Bioinformatics 5:26

51. Poon TC, Hui AY, Chan HL, Ang IL, Chow SM, Wong N, Sung JJ 2005 Prediction of liver fibrosis and cirrhosis in chronic hepatitis B infection by serum proteomic fingerprinting: a pilot study. Clin Chem 51:328-335

52. Gravett MG, Novy MJ, Rosenfeld RG, Reddy AP, Jacob T, Turner M, McCormack A, Lapidus JA, Hitti J, Eschenbach DA, Roberts CT, Nagalla SR 2004 Diagnosis of intra-amniotic infection by proteomic profiling and identification of novel biomarkers. JAMA 292:462-469

53. Madan A, El-Ferzli G, Carlson SM, Whitin JC, Schilling J, Najmi A, Yu TT, Lau K, Dimmitt RA, Cohen HJ 2007 A potential biomarker in the cord blood of preterm infants who develop retinopathy of prematurity. Pediatr Res 61:215-221
54. Buhimschi CS, Bhandari V, Hamar BD, Bahtiyar MO, Zhao G, Sfakianaki AK, Pettker CM, Magloire L, Funai E, Norwitz ER, Paidas M, Copel JA, Weiner CP, Lockwood CJ, Buhimschi IA 2007 Proteomic profiling of the amniotic fluid to detect inflammation, infection, and neonatal sepsis. PLoS Med 4:e18

55. Petricoin EF, Zoon KC, Kohn EC, Barrett JC, Liotta LA 2002 Clinical proteomics: translating benchside promise into bedside reality. Nat Rev Drug Discov 1:683-695

56. Jiang P, Siggers JL, Ngai HH, Sit WH, Sangild PT, Wan JM 2008 The small intestine proteome is changed in preterm pigs developing necrotizing enterocolitis in response to formula feeding. J Nutr 138:1895-1901

57. Chertov O, Simpson JT, Biragyn A, Conrads TP, Veenstra TD, Fisher RJ 2005 Enrichment of low-molecular-weight proteins from biofluids for biomarker discovery. Expert Rev Proteomics 2:139-145

58. Tabuse Y, Nabetani T, Tsugita A 2005 Proteomic analysis of protein expression profiles during Caenorhabditis elegans development using two-dimensional difference gel electrophoresis. Proteomics 5:2876-2891

59. Park JS, Oh KJ, Norwitz ER, Han JS, Choi HJ, Seong HS, Kang YD, Park CW, Kim BJ, Jun JK, Syn HC 2008 Identification of proteomic biomarkers of preeclampsia in amniotic fluid using SELDI-TOF mass spectrometry. Reprod Sci 15:457-468

60. Iacobas DA, Suadicani SO, Iacobas S, Chrisman C, Cohen MA, Spray DC, Scemes E 2007 Gap junction and purinergic P2 receptor proteins as a functional unit: insights from transcriptomics. J Membr Biol 217:83-91

61. Mai V 2004 Dietary modification of the intestinal microbiota. Nutr Rev 62:235-242 